\title{
Understanding the dynamics of lion attacks on humans and livestock in southern Maasailand, Kenya
}

\author{
Guy Western, David W. Macdonald, Andren J. Loveridge \\ Amy J. Dickman, Peter Tyrrell and Samantha Russell
}

\begin{abstract}
Negative interactions with humans resulting from livestock predation is a major factor influencing the decline of African lion Panthera leo populations across Africa. Here we investigate lion depredation within two Maasai communities in southern Kenya where people and lions coexist in the absence of any formal protected areas. We explore the factors that increase the frequency and severity of lion attacks on pastoralists and their livestock and assess the effectiveness of livestock guarding to reduce damage. Finally, we examine in which circumstances lion depredation triggers retaliation by people. Over a period of 26 months, lions attacked livestock 29 times, resulting in 41 livestock deaths and 19 injuries. There were also two attacks on people. Lions preferred cattle over the more numerous sheep and goats. Attacks on livestock occurred mostly during the dry season and were not affected by changes in prey density or variation in pastoral settlement that brought livestock into closer proximity with lions. Livestock were guarded during $48.2 \%$ of lion attacks. Active guarding at pasture disrupted the majority of lion attacks, resulting in lower mortality rates. Passive guarding in corrals at night also disrupted attacks but did not lead to lower livestock mortality.
\end{abstract}

Keywords Community conservation, conflict, humanwildlife interactions, lion, livestock depredation, Maasai, Panthera leo

Supplementary material for this article is available at doi.org/10.1017/So030605319000826

\section{Introduction}

$\mathrm{T}$ he rapid collapse of African lion Panthera leo populations and range, mainly because of anthropogenic pressures, is a challenge for the conservation of large carnivores (Lindsey et al., 2017). Historically, lions were one of the most widespread terrestrial mammals, ranging from northern

GUY WESTERN* (Corresponding author, (D) orcid.org/0000-0001-6866-766X), David W. Macdonald, Andrew J. Loveridge, Amy J. Dickman and Peter TyrRell* Department of Zoology, Wildlife Conservation Research Unit, University of Oxford, Recanati-Kaplan Centre, Tubney House, Abingdon Road, Tubney, Oxfordshire, OX13 5QL, UK. E-mail gwestern@soralo.org

Samantha Russell South Rift Association of Landowners, Nairobi, Kenya

*Also at: South Rift Association of Landowners, Nairobi, Kenya

Received 27 March 2018. Revision requested 12 June 2018.

Accepted 15 July 2019. First published online 11 December 2020.
Europe to southern Africa, but are now confined to $<8 \%$ of their former range. Lion populations are estimated to have decreased by $43 \%$ since 2000 , to $23,000-35,000$ individuals (Bauer et al., 2015a). Lion populations outside protected areas still comprise a substantial part of the species' current range, which means that Africa's protected area network alone may be insufficient to secure metapopulations of lions across their range (Crooks et al., 2011; Dolrenry et al., 2014).

Negative human-lion interactions resulting from livestock predation are a major driver of the decline of lion populations (Lindsey et al., 2017; Loveridge et al., 2017). Across Eastern Africa's livestock- and human-dominated landscapes, carnivore attacks on livestock occur frequently and can lead to retaliatory and preventative killings of lions (Hazzah et al., 2009). In Kenya predators on private and communal ranches can kill $2-3 \%$ of the total livestock herd annually (Maclennan et al., 2009; Bauer et al., 2015b). Although lions are responsible for a small proportion of these attacks, they are often disproportionately persecuted (Kissui, 2008). The prevalence of retaliatory killing of lions has led to conservation efforts aimed at reducing depredation, to enable coexistence between people and carnivores on private and communal lands (Creel et al., 2013).

In Eastern Africa's rangelands, Maasai pastoralists traditionally relied on killing carnivores and guarding livestock to reduce livestock depredation (Spencer, 1988). However, many Maasai communities in Kenya, such as those in Olkiramatian and Shompole, now actively engage in community-based conservation initiatives and are choosing to refrain from lethal control of carnivores. This leaves livestock guarding as the main tool to reduce depredation (Schuette et al., 2013). Keeping livestock in corrals at night and active herding at pasture during the day are effective guarding practices employed by Maasai pastoralists (Woodroffe et al., 2007; Bauer et al., 2015b). Meta-analyses of previous studies have shown that corralling livestock at night reduces depredation by a range of carnivores, including lions, pumas Puma concolor and spotted hyaenas Crocuta crocuta, but the effectiveness of this practice appears to be highly context-specific and dependent on the type of corral used (Eklund et al., 2017). Data on the effectiveness of active herding from different areas are contradictory. For example, guarding by herders reduced the severity of wolf Canis lupus attacks on sheep in Greece (Iliopoulos et al., 2009), but near Golestan National Park in Iran the majority (92.5\%) of livestock losses to leopards occurred when a herder was present (Khorozyan et al., 2017). 
Given that a large proportion of lions and other carnivores occur in human-dominated landscapes (Crooks et al., 2011), evaluating whether guarding practices such as those in Maasailand can reduce the severity of livestock attacks can help inform carnivore conservation. Here we focused on two communally owned Maasai ranches in Kenya (Olkiramatian and Shompole) where lions and other large carnivores still persist beyond national parks and reserves (Schuette et al., 2013). We focused on three main questions: (1) What are the anthropogenic and environmental factors that influence the frequency and severity of lion attacks on livestock? (2) Does guarding reduce the severity of lion attacks on livestock? (3) In which circumstances do lion attacks on livestock or humans trigger retaliation?

\section{Study area}

We conducted research on Olkiramatian and Shompole group ranches, two communally owned and managed ranches in the South Rift region of Kenya. Transhumance Maasai pastoralists occupy the area, migrating seasonally in search of water and pasture. The region is semi-arid, with annual rainfall of $200-600 \mathrm{~mm}$ (Schuette et al., 2013). The Ewaso Nyiro river runs through the two group ranches, providing a permanent source of water that is important for both livestock and wildlife. The two group ranches collectively cover $890 \mathrm{~km}^{2}$, with habitats including dense Acacia tortillis woodland, Salvador persica bushland and open grassland (Fig. 1).

In 2000 and 2004, Shompole and Olkiramatian communities set aside conservation areas on the western banks of the Ewaso Nyiro river, covering $450 \mathrm{~km}^{2}\left(400 \mathrm{~km}^{2}\right.$ core conservancy and $50 \mathrm{~km}^{2}$ buffer zones). No settlement is allowed in the core areas but seasonal grazing is permitted during periods of low pasture availability (SeptemberMarch), whereas in the buffer zones seasonal grazing and settlement are permitted. Locally elected group ranch and conservation committees govern grazing and settlement within the conservation areas.

Olkiramatian and Shompole group ranches have high densities of livestock and wild ungulates (sheep/goats: 59.1 individuals $/ \mathrm{km}^{2}$; cattle: $15.8 / \mathrm{km}^{2}$; wild ungulates: $28.2 / \mathrm{km}^{2}$; Schuette et al., 2016). The lion density in the conservation areas is 0.136 adult lions $/ \mathrm{km}^{2}$ (Schuette et al., 2013).

\section{Methods}

\section{Collection of data on lion attacks}

GW trained a team of five local Maasai research assistants to document and verify incidents of lion depredation. We defined depredation as verified cases of lion attacks on people or livestock, and damage as the total number of livestock

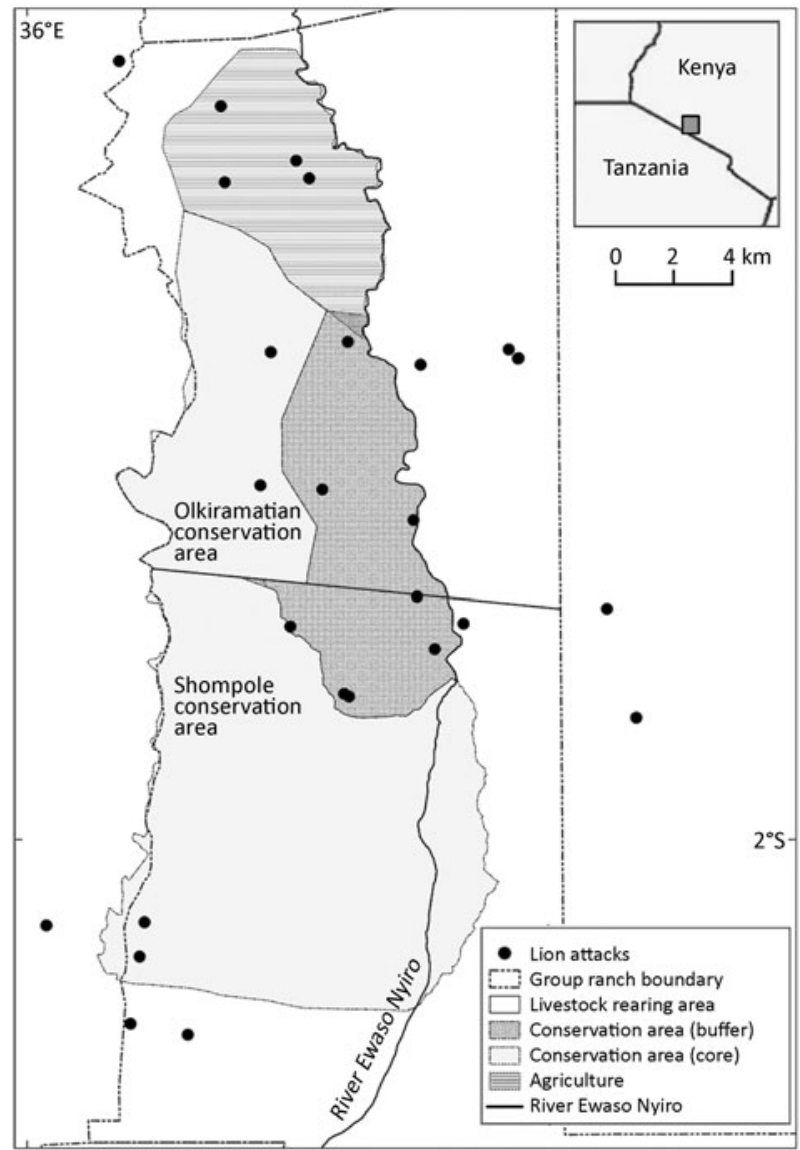

FIG. 1 Study area showing locations of lion attacks on livestock, group ranch boundaries, conservation areas (core and buffer), and settlement locations.

or people killed and injured during a depredation incident. During September 2014-November 2016, lion depredation incidents were also reported to one of three entities: the Kenya Wildlife Service, our research team or the South Rift Association of Land Owners community rangers. When an incident was reported at least one member of our research team investigated and verified the case using visual inspection of injuries and carcasses, and of signs and spoor to reconstruct the attack. Only verified incidents and damage were used for further analysis. Isolated incidents of depredation may have gone unreported, but we assume this reporting bias remained constant throughout the study period, thus allowing patterns of depredation to be examined.

We grouped depredation incidents into four categories, based on their context: (1) within the boma (inside community homesteads), (2) adjacent to the boma (within $200 \mathrm{~m}$ of the boma but not enclosed within it), (3) grazing at pasture, and (4) lost livestock (livestock became separated and did not return to the homestead with the main herd). In addition, we recorded whether livestock were being guarded when the attack occurred, with three categories: (1) passive 
guarding (livestock inside corral at night, no herder present), (2) active guarding (outside the homestead, herder present) and (3) no guarding. We categorized lion attacks as (1) disrupted (herders disturbed the attack, which resulted in non-fatal attacks on livestock or fatal attacks during which lions were unable to consume the livestock) or (2) undisrupted (lions killed and consumed livestock).

\section{Collection of data on anthropogenic and environmental factors}

We included rainfall, season, prey and livestock density, pasture availability, changes in human settlement, and cattle ranging distance as contextual variables in our analysis.

We measured rainfall using a $\mathrm{HOBO} \mathrm{UB}_{3} 0$ automated weather station (HOBO Data Loggers Australia, Adelaide, Australia) located centrally within the study area, which generated monthly totals. Season was based on median monthly rainfall, whereby months with $\leq 26.80 \mathrm{~mm}$ were categorized as dry and those with more as wet.

We measured prey and livestock density using point counts conducted at 60 randomly selected locations across the area. We conducted point counts 16 times throughout the study period (c. once every 6 weeks) and recorded all wild ungulates and livestock visible within $400 \mathrm{~m}$ of the observation point. We then calculated a metric of wild ungulate and livestock density for each of the 16 sampling periods using the Jolly 2 analysis (Jolly, 1969) and interpolated to create a monthly measure of density. Lions in the study area preferred zebra Equus quagga and wildebeest Connochaetes taurinus over other potential prey species (Creel et al., 2014), thus we combined monthly zebra and wildebeest densities to provide a monthly index of wild prey abundance. Similarly, we used the combined monthly densities of cattle, sheep, goats and donkeys as the index of livestock abundance.

We used data for pasture availability (grass biomass in $\mathrm{g} / \mathrm{m}^{2}$ ) from Russell et al. (2018), who measured grass biomass using 23 randomly selected vegetation plots, which were sampled 16 times during the study period (c. once every 6 weeks). Russell et al. (2018) used the pin intercept method to produce a measure of total grass biomass (Mwangi \& Western, 1998; Sutherland, 2008), and categorized results as low and high (median monthly biomass $\leq 70$ and $>70 \mathrm{~g} / \mathrm{m}^{2}$, respectively).

We mapped human settlements monthly as an indicator of livestock and human presence across the area. This included the locations of bomas, whether they were temporary or permanent, occupied or unoccupied, the type of livestock present, and the names of the families occupying the homestead. We calculated the number of occupied settlements within the study area and used the seasonal presence of settlements in the buffer zone as a proxy for human presence within the conservation areas (Fig. 1).
The livestock ranging distance (i.e. distance livestock travel from the homestead on a given day) is closely related to the mean monthly normalized distance vegetation index, which categorizes vegetation by measuring the reflectivity of different surfaces, using satellite images (Butt, 2010; Turner et al., 2016). It was not logistically possible to track all livestock herds (sheep, goats and cattle) within the study area with a GPS, so we used the mean monthly normalized distance vegetation index as a reliable index of livestock ranging distance. We created monthly estimates using MODIS tools in $R$ 3.3.o (Mattiuzzi \& Detsch, 2017), which extracted 16-day composites from 20 randomly selected sites across the area at $250 \mathrm{~m}$ resolution.

\section{Data analysis}

We used $R$ for all data analyses. We summarized the frequency of lion attacks on people and livestock using the total number of incidents (n). We calculated the severity of damage (mean number of livestock killed and injured per incident), by incident type, and mean mortality (number of fatalities per incident). We used $\chi^{2}$ and Kruskal-Wallis tests to compare mean livestock mortality and livestock damage in the presence vs absence of herders, for disrupted vs undisrupted attacks, and in different contexts of attacks.

We used the Jacobs selection index (Jacobs, 1974) to test whether lions preferred small livestock (sheep and goats), donkeys or cattle. We assessed the variation in the frequency of lion depredation on livestock by season, presence of settlements and context using Kruskal-Wallis, $\chi^{2}$ and Mann-Whitney U (Wilcoxon rank sum) tests.

\section{Model formulation}

We used five variables (rainfall, prey density, livestock density, pasture availability and presence of settlements) to create predictive generalized linear models of the monthly frequency of livestock depredation. To account for possible interaction between livestock densities, prey densities and rainfall, we included interaction terms in the model formulation. Prior to model formulation, we calculated variance inflation factors for all five predictor variables to assess multicollinearity and excluded variables with variance inflation factors $>_{3}$ (Zuur et al., 2010). Subsequently, we used Pearson's correlation to investigate pairwise relationships between predictor variables. We used the $R$ package package Mass (Ripley, 2015) to assess whether the response variable (count data) best conformed to a Poisson distribution or to a negative binomial distribution. Finally, we used the $R$ package MuMin (Barton, 2016) to create and compare a full set of predictive models based on Akaike's information criterion corrected for small sample size (AICc; Symonds \& Moussalli, 2011). 
TABle 1 Overview of lion Panthera leo depredation on different species of livestock by context, showing the number of depredation incidents, total number of livestock killed and injured (livestock damage) and total number of livestock killed (livestock mortality).

\begin{tabular}{|c|c|c|c|c|c|}
\hline & \multicolumn{3}{|c|}{ Context of attacks } & \multirow[b]{2}{*}{ Lost livestock } & \multirow[b]{2}{*}{ Total } \\
\hline & In boma & Adjacent to boma & At pasture & & \\
\hline \multicolumn{6}{|c|}{ Number of depredation incidents } \\
\hline Cattle & 3 & 0 & 8 & 5 & 16 \\
\hline Sheep \& goats & 5 & 0 & 1 & 2 & 8 \\
\hline Donkeys & 0 & 5 & 0 & 0 & 5 \\
\hline Total no. of incidents & 8 & 5 & 9 & 7 & 29 \\
\hline \multicolumn{6}{|l|}{ Total livestock damage } \\
\hline Cattle & 13 & 0 & 11 & 6 & 30 \\
\hline Sheep \& goats & 13 & 0 & 2 & 8 & 23 \\
\hline Donkeys & 0 & 7 & 0 & 0 & 7 \\
\hline Total livestock damage & 26 & 7 & 13 & 14 & 60 \\
\hline Mean damage per incident & 3.25 & 1.40 & 1.44 & 2.00 & 2.07 \\
\hline \multicolumn{6}{|l|}{ Total livestock mortality } \\
\hline Cattle & 7 & 0 & 4 & 6 & 17 \\
\hline Sheep \& goats & 11 & 0 & 1 & 8 & 20 \\
\hline Donkeys & 0 & 4 & 0 & 0 & 4 \\
\hline Total livestock mortality & 18 & 4 & 5 & 14 & 41 \\
\hline Mean mortality per incident & 2.25 & 0.80 & 0.56 & 2.00 & 1.41 \\
\hline
\end{tabular}

TABLE 2 Overview of lion depredation on livestock, showing the number of depredation incidents, livestock killed and injured (livestock damage), and livestock killed (livestock mortality).

\begin{tabular}{|c|c|c|c|c|c|}
\hline & \multirow[b]{2}{*}{ Incidents } & \multicolumn{2}{|c|}{ Livestock damage } & \multicolumn{2}{|c|}{ Livestock mortality } \\
\hline & & Total & Mean per incident & Total & Mean per incident \\
\hline \multicolumn{6}{|l|}{ Season } \\
\hline Dry & 23 & 53 & 2.30 & 37 & 1.68 \\
\hline Wet & 6 & 7 & 1.17 & 4 & 0.67 \\
\hline \multicolumn{6}{|c|}{ Human settlements present } \\
\hline Yes & 20 & 39 & 1.95 & 29 & 1.45 \\
\hline No & 9 & 21 & 2.33 & 12 & 1.50 \\
\hline \multicolumn{6}{|l|}{ Context of attack } \\
\hline In boma & 8 & 26 & $3.25^{*}$ & 18 & $2.25^{\star *}$ \\
\hline Adjacent to boma & 5 & 7 & 1.40 & 4 & 0.80 \\
\hline At pasture & 9 & 13 & 1.44 & 5 & 0.56 \\
\hline Lost livestock & 7 & 14 & 2.00 & 14 & 2.00 \\
\hline \multicolumn{6}{|l|}{ Guarding present } \\
\hline Yes & 14 & 34 & $2.43^{* *}$ & 21 & 1.50 \\
\hline No & 15 & 26 & 1.73 & 20 & 1.33 \\
\hline \multicolumn{6}{|l|}{ Type of guarding } \\
\hline Active & 6 & 8 & 1.33 & 3 & 0.50 \\
\hline Passive & 8 & 26 & 3.25 & 18 & $2.25^{\star \star}$ \\
\hline None & 15 & 26 & 1.73 & 20 & 1.33 \\
\hline \multicolumn{6}{|l|}{ Attack disrupted } \\
\hline Yes & 13 & 26 & 2.00 & 13 & 1.00 \\
\hline No & 16 & 34 & 2.13 & 28 & 1.75 \\
\hline
\end{tabular}

${ }^{*} \mathrm{P}<0.05 ;{ }^{* * \mathrm{P}}<0.01$.

\section{Results}

A total of 31 lion depredation incidents, including 29 on livestock and two on people, were reported and verified during the study period. During the two attacks on people, three people were injured. The total livestock damage was 6o (41 killed, 19 injured; Tables 1 \& 2). Mean livestock damage was 2.07 livestock per incident (range $=1-8$ ), and mean mortality was 1.41 (range $=1-7$ ). Based on an estimated population of $42,350 \pm$ SE 13,480 livestock in the study area (Tyrrell et al., 2017), the mean annual livestock damage caused by lions was $0.07 \%$. 

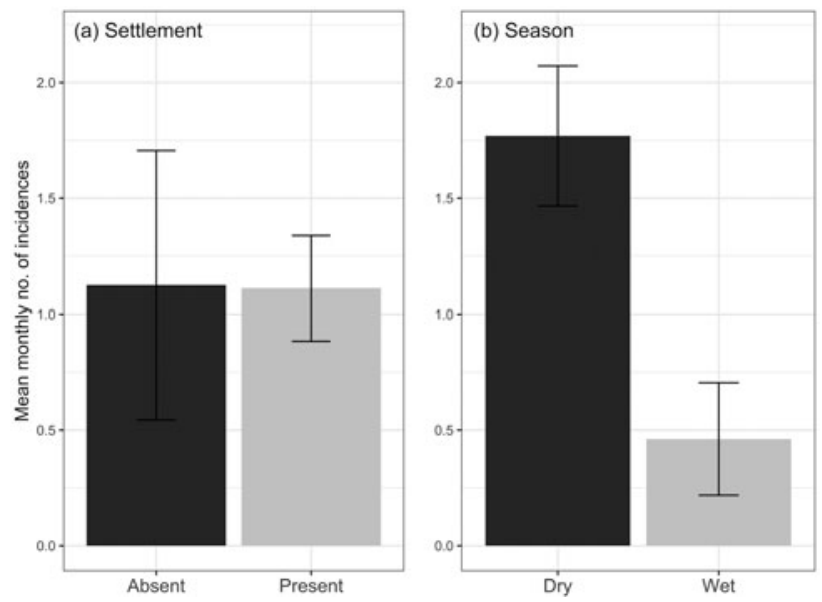

FIG. 2 Mean monthly frequency of lion depredation (with standard error bars) (a) when human settlements were present or absent in the conservation areas, and (b) during different seasons.

\section{Context of attacks}

The two lion attacks on people occurred when herders went in search of lost livestock. Lion attacks on livestock did not predominantly occur in any particular context $\left(\chi^{2}=1.20\right.$, $\mathrm{df}=3, \mathrm{P}=0.751)$; the total numbers of incidents categorized as in boma $(\mathrm{n}=8)$, adjacent to boma $(\mathrm{n}=5)$, at pasture $(\mathrm{n}=9)$ and lost livestock $(\mathrm{n}=7)$ were similar. However, a single lioness who had been translocated from the southern end of the study area to the north after being caught in a leopard trap was responsible for 5 of the 8 lion attacks inside a boma.

The severity of lion attacks on livestock was influenced by the context of the attack (Table 2). Mean livestock mortality per incident was highest in boma ( 2.22 livestock per incident) and lowest at pasture (0.56 livestock per incident; Kruskal Wallis $=12.72, \mathrm{P}=0.005)$. The Jacobs index analysis showed that lions had a preference for large (donkeys $=0.89$, cattle $=0.83$ ) over small livestock (sheep and goats $=-0.89$ ). Lions attacked cattle most frequently at pasture (Fisher's exact test, $\mathrm{P}<0.001)$, with $27 \%(\mathrm{n}=8)$ of all lion attacks and $50 \%(\mathrm{n}=8)$ of lion attacks on cattle being recorded in this context. Small livestock was mostly attacked in boma (Table 1).

Human and livestock presence within the conservation area did not affect the frequency of lion attacks on livestock $\left(\chi^{2}=0.47, \mathrm{df}=1, \mathrm{P}=0.491\right)$; attacks occurred during $55.0 \%(\mathrm{n}=11)$ of the months when settlements were present $(n=20)$ and $50.0 \%(n=3)$ of months when settlements were absent $(n=6)$. Lion depredation incidents per month were not significantly different in months with and without settlements (Wilcox test, $W=75, \mathrm{P}=0.89$; Fig. 2). Season did influence the frequency of lion depredation, which occurred during $76.9 \%(n=11)$ of dry months and only $30.8 \%(n=4)$
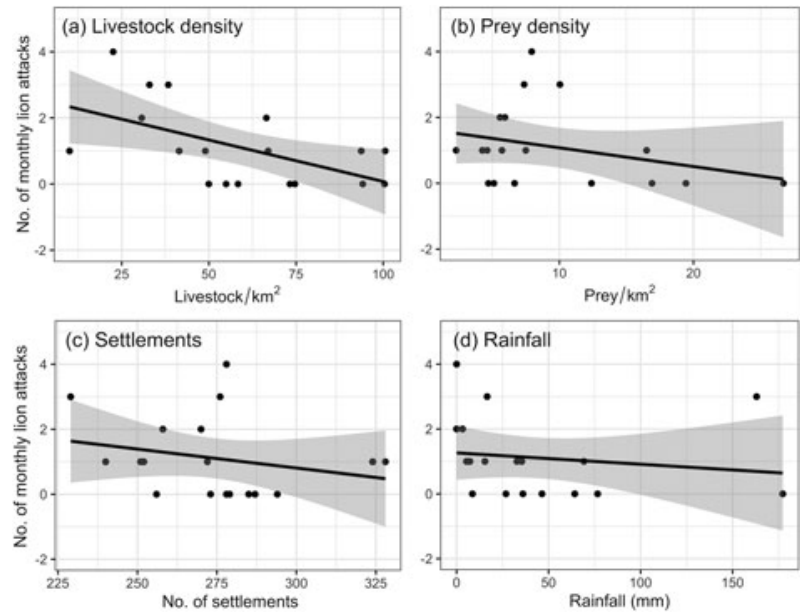

FIG. 3 Line graphs depicting linear relationships (solid lines) with $95 \%$ confidence intervals (grey areas) between the prevalence of lion attacks (dots) and the four explanatory variables that were included in model formulation: (a) livestock density, (b) prey density, (c) settlements and (d) rainfall.

of wet months $\left(\chi^{2}=3.869, \mathrm{df}=1, \mathrm{P}=0.049\right)$. The mean number of depredation incidents per month was also greater during dry months than during wet months (Wilcox test, $W=41.5, \mathrm{P}=0.02$; Fig. 2).

\section{Predicting frequency of livestock depredation}

We tested rainfall, pasture availability, prey and livestock density, presence of settlements, and cattle ranging distance for any impact on the frequency of lion attacks on livestock. There was collinearity (variance inflation factor $>3$ ) between several of the predictor variables. Pearson pairwise comparisons showed a correlation between pasture availability and livestock ranging distance $\left(r_{\mathrm{p}}=0.81, \mathrm{P}<0.01\right)$, and between livestock ranging distance and prey density $\left(r_{\mathrm{p}}=0.71, \mathrm{P}<0.01\right)$. We therefore excluded pasture availability from the model and used prey density to represent pasture availability and livestock ranging distance.

The livestock density model was the best predictor and explained $34 \%$ of variance of livestock depredation (Fig. 3). This model was a better predictor $(\triangle \mathrm{AICc}=2.68)$ of depredation frequency than an expanded model containing livestock and prey density. Models that included only prey abundance, presence of settlements or rainfall performed worse than the null model which included only the intercept (Supplementary Table 1).

\section{Livestock guarding and disrupted attacks}

Livestock were guarded during $48.3 \%(n=14)$ of all lion attacks, with active guarding during $20.7 \%(\mathrm{n}=6)$ and passive guarding during $27.6 \%(\mathrm{n}=8)$ of attacks. Although livestock guarding is a common practice in the study area, 
$50.3 \%$ of attacks were on unguarded livestock that were either lost at pasture or left outside corrals.

The type of livestock guarding influenced its effectiveness (Table 2), with attacks on passively guarded livestock being more severe (mean mortality $=2.25$ livestock per incident) than those on actively guarded livestock (mean mortality $=0.50$ livestock per incident).

Livestock owners and herders disrupted $44.8 \%(n=13)$ of lion attacks on livestock, whereby active guarding disrupted $75 \%(\mathrm{n}=5)$ of attacks at pasture and passive guarding (corralling and sleeping next to livestock) disrupted $62.5 \%$ $(n=5)$ of attacks in boma. Of the other three disrupted attacks, in two cases lions were chased off by herders who were grazing their livestock nearby and were alerted by the noise caused by the lion attacks, and in the third case herders harassed lions who had attacked a donkey outside their boma.

\section{Retaliatory lion hunts}

There were two retaliatory hunts in response to lion attacks during the study period. The first was after a single lioness had attacked small livestock in bomas five times in a 10day period. Prior to the hunt, community members had requested the wildlife authorities to deal with the lioness but no action was taken. The second incident occurred when a member of the community was mauled by a lioness while he was in search of lost livestock. In both hunts men carried spears, more than 20 participants were involved, and the lionesses responsible for the attacks were killed.

\section{Discussion}

\section{Patterns of depredation}

Livestock owners in Olkiramatian and Shompole, as in other areas, actively and passively guarded their livestock during the study period. Despite this, depredation by lions still occurred, demonstrating that livestock guarding may reduce but not necessarily prevent lion attacks. In other Maasai areas such as the Mara and Tarangire ecosystems, herders deter lions that attack livestock at pasture, and fortifying traditional Maasai bomas has been shown to further reduce livestock predation (Kolowski \& Holekamp, 2006; Lichtenfeld et al., 2015). Our findings suggest that several variables determined the severity of lion attacks.

Lions in Olkiramatian and Shompole preferred large livestock (cattle and donkeys) over small stock (sheep and goats) despite small stock being four times more abundant (Russell et al., 2018). Elsewhere, lions also prefer medium to large domestic or wild prey (i.e. ungulates weighing $190-550 \mathrm{~kg}$; Hayward \& Kerley, 2005; Loveridge et al., 2017). The lions' preference for cattle over small livestock potentially increases the impact of attacks on Maasai communal lands because cattle are particularly important for Maasai identity and livelihoods (Spencer, 1988). However, in Olkiramatian and Shompole no retaliatory hunts occurred as a direct result of cattle predation.

Lion attacks on cattle occurred mostly at pasture, whereas sheep and goats were attacked in bomas and donkeys adjacent to bomas, which partially explains why livestock mortality was highest in bomas and lowest at pasture. The severity of depredations in boma could be compounded by the confinement of livestock in corrals. Livestock was frequently lost at pasture, which accounted for a large proportion of livestock mortality $(34.1 \%, n=14)$ during the study period. Although guarding livestock and searching for lost animals are necessary to protect livestock, these activities also carry risks and could escalate human-lion conflicts as herders may be attacked in the process (as was the case in both lion attacks on people in this study).

\section{Predicting lion attacks on livestock}

Lion depredation on livestock in Olkiramatian and Shompole caused an annual damage (death and injury) of $0.07 \%$ of total livestock. By comparison Kuku group ranch in southern Kenya Maasai lost $0.49 \%$ of their livestock per year to lions (Bauer et al., 2015b), and predators caused $2.4 \%$ of livestock losses in the Tsavo region, with lions being responsible for $86 \%$ of attacks (Patterson et al., 2004).

Most lion attacks occurred during the dry season when livestock densities were lowest. Seasonal patterns of prey and livestock movements may explain this counter-intuitive result. In the study area, pastoralists often migrated with their herds out of the area in search of grazing (Tyrrell et al., 2017) during periods of poor pasture. The remaining herds of livestock and wild ungulates concentrated on the remaining patches of good-quality pasture, which were predominantly located in swamps and closed woodlands that were also used by lions as daytime resting areas (Schuette et al., 2013; Russell et al., 2018).

Our findings contrast with previous studies in which livestock predation rates increased during the wet season when wild prey is less abundant (Kissui, 2008; Loveridge et al., 2017). The shift from wild to domestic prey has been linked to reduced prey abundance, with lions switching to livestock predation when wild prey biomass falls below a threshold of $812 \mathrm{~kg} / \mathrm{km}^{2}$ (Khorozyan et al., 2015). We found no significant relationship between prey density and the frequency of livestock predation, suggesting that lions within Olkiramatian and Shompole had sufficient wild prey.

Livestock ranging distance and the presence of settlements within the buffer zones of the conservation area did not increase the frequency of lion attacks. In Olkiramatian and Shompole lions and wild ungulates shifted away from the buffer zone to core conservation areas when settlements were present (Schuette et al., 2013, 2016). This shift in 
ungulate distribution increases prey availability in the conservancies and may offset the increased likelihood of human-lion encounters when livestock are grazing within the conservation areas.

\section{Lion attacks on people and retaliatory killing}

Communities in the study area were remarkably tolerant towards lions attacking livestock. By contrast, in the Maasai steppe region of Tanzania people were less tolerant, with retaliatory killing of 85 lions in a 19-month period (Kissui, 2008). Retaliatory killing in Maasai communities has been linked to a higher proportion of livestock lost, and engagement in commercial livestock rearing (Hazzah et al., 2009). Our sample size was not large enough to clearly identify triggers of retaliation but serial livestock depredation by individual lions and attacks on people are probable factors.

In summary, our findings suggest that guarding against and disrupting lion attacks can reduce livestock mortality. However, the safety of herders and people searching for lost livestock should be considered so that these activities do not result in human fatalities or retaliatory lion hunts. Rapid response teams to assist in the recovery of lost livestock and attend to cases of human-wildlife conflict could be one way of achieving this. In addition, databases for storing information on incidents of human-wildlife conflict, and protocols to facilitate reports of lost livestock and lion attacks, could provide conservation managers and stakeholders with accurate and timely information.

Acknowledgements We thank the Cincinnati Zoo and Botanical Gardens, the Akron Zoo and Panthera for funding, the communities in Olkiramatian and Shompole who continue to conserve lions and allowed us to conduct our research, and the resource assessors for support with data collection.

Author contributions Study design, data collection and analysis, writing: GW; additional data: SR; revisions: all authors.

\section{Conflicts of interest None.}

Ethical standards This research complied with the Oryx guidelines on ethical standards. Research was led by the South Rift Association of Landowners, a Kenyan community-based organization. Permission to conduct the research was acquired through the University of Oxford and African Conservation Centre. Our research did not involve experimentation on human or animal subjects. All data and the findings of this study are freely available to the members of the Olkiramatian and Shompole community.

\section{References}

Barton, K. (2016) MuMin: multi-model inference. $R$ package version 1.15.6.2016. cran.r-project.org/web/packages/MuMIn/MuMIn.pdf [accessed July 2018].

Bauer, H., Chapron, G., Nowell, K., Henschel, P., Funston, P., Hunter, L.T. et al. (2015a) Lion (Panthera leo) populations are declining rapidly across Africa, except in intensively managed areas. Proceedings of the National Academy of Sciences of the United States of America, 112, 14894-14899.

Bauer, H., Müller, L., van der Goes, D. \& Sillero-Zubiri, C. (2015b) Financial compensation for damage to livestock by lions Panthera leo on community rangelands in Kenya. Oryx, 51, 106-114.

Butт, B. (2010) Seasonal space-time dynamics of cattle behavior and mobility among Maasai pastoralists in semi-arid Kenya. Journal of Arid Environments, 74, 403-413.

Creel, S., Becker, M., Durant, S., M’soka, J., Matandiko, W., Dickman, A. et al. (2013) Conserving large populations of lions the argument for fences has holes. Ecology Letters, 16, 1413-e3.

Creel, S., Schuette, P. \& Christianson, D. (2014) Effects of predation risk on group size, vigilance, and foraging behavior in an African ungulate community. Behavioral Ecology, 25, 773-784.

Crooks, K.R., Burdett, C.L., Theobald, D.M., Rondinini, C. \& Bortani, L. (2011) Global patterns of fragmentation and connectivity of mammalian carnivore habitat. Philosophical Transactions of the Royal Society of London B: Biological Sciences, $366,2642-2651$.

Dolrenry, S., Stenglein, J., Hazzah, L., Lutz, R.S. \& Frank, L. (2014) A metapopulation approach to African lion (Panthera leo) conservation. PLOS ONE, 9, e88081.

Eklund, A., López-Bao, J.V., Tourani, M., Chapron, G. \& Frank, J. (2017) Limited evidence on the effectiveness of interventions to reduce livestock predation by large carnivores. Scientific Reports, 7, 2097.

Hayward, M.W. \& Kerley, G.I. (2005) Prey preferences of the lion (Panthera leo). Journal of Zoology, 267, 309-322.

Hazzah, L., Mulder, M.B. \& Frank, L. (2009) Lions and warriors: social factors underlying declining African lion populations and the effect of incentive-based management in Kenya. Biological Conservation, 142, 2428-2437.

Iliopoulos, Y., S Gardelis, S., Koutis, V. \& SAVAris, D. (2009) Wolf depredation on livestock in central Greece. Mammal Research, $54,11-22$.

JACOBS, J. (1974) Quantitative measurement of food selection. Oecologia, 14, 413-417.

Jolly, G. (1969) Sampling methods for aerial censuses of wildlife populations. East African Agricultural and Forestry Journal, $34,46-49$.

Khorozyan, I., Ghoddousi, A., Soofi, M. \& Waltert, M. (2015) Big cats kill more livestock when wild prey reaches a minimum threshold. Biological Conservation, 192, 268-275.

Khorozyan, I., Soofi, M., Soufi, M., Hamidi, A.K., Ghoddousi, A. \& Waltert, M. (2017) Effects of shepherds and dogs on livestock depredation by leopards (Panthera pardus) in north-eastern Iran. PeerJ, 5, e3049.

KIssui, B. (2008) Livestock predation by lions, leopards, spotted hyenas, and their vulnerability to retaliatory killing in the Maasai steppe, Tanzania. Animal Conservation, 11, 422-432.

Kolowski, J. \& Holekamp, K. (2006) Spatial, temporal, and physical characteristics of livestock depredations by large carnivores along a Kenyan reserve border. Biological Conservation, 128, 529-541.

Lichtenfeld, L.L., Trout, C. \& Kisimir, E.L. (2015) Evidence-based conservation: predator-proof bomas protect livestock and lions. Biodiversity and Conservation, 24, 483-491.

Lindsey, P., Petracca, L., Funston, P., Bauer, H., Dickman, A., Everatt, K. et al. (2017) The performance of African protected areas for lions and their prey. Biological Conservation, 209, 137-149.

Loveridge, A.J., Kuiper, T., Parry, R.H., Sibanda, L., Hunt, J.H., STAPELKAMP, B. et al. (2017) Bells, bomas and beefsteak: complex 
patterns of human-predator conflict at the wildlife-agropastoral interface in Zimbabwe. PeerJ, 5, e2898.

Maclennan, S.D., Groom, R.J., Macdonald, D.W. \& Frank, L.G. (2009) Evaluation of a compensation scheme to bring about pastoralist tolerance of lions. Biological Conservation, 142, 2419-2427.

Mattiuzi, M. \& Detsch, F. (2017) MODIS: Acquisition and processing of MODIS products. $R$ package version 1.1. cran.r-project. org/web/packages/MODIS/MODIS.pdf [accessed July 2018].

Mwangi, E. \& Western, D. (1998) Fluctuations in food supply in an insularized and heavily grazed savanna ecosystem in Kenya. African Journal of Ecology, 36, 207-212.

Patterson, B.D., Kasiki, S.M., Selempo, E. \& Kays, R.W. (2004) Livestock predation by lions (Panthera leo) and other carnivores on ranches neighboring Tsavo National Parks, Kenya. Biological Conservation, 119, 507-516.

Ripley, B. (2015) MASS: support functions and datasets for Venables and Ripley's MASS. cran.r-project.org/package=MASS [accessed 16 January 2020].

Russell, S., Tyrrell, P. \& Western, D. (2018) Seasonal interactions of pastoralists and wildlife in relation to pasture in an African savanna ecosystem. Journal of Arid Environments, 154, 70-81.

Schuette, P., Creel, S. \& Christianson, D. (2013) Coexistence of African lions, livestock, and people in a landscape with variable human land use and seasonal movements. Biological Conservation, $157,148-154$.
Schuette, P., Creel, S. \& Christianson, D. (2016) Ungulate distributions in a rangeland with competitors, predators and pastoralists. Journal of Applied Ecology, 53, 1066-1077.

Spencer, P. (1988) The Maasai of Matapato: A Study of Rituals of Rebellion. Manchester University Press, Manchester, UK.

Sutherland, W.J. (2008) The Conservation Handbook: Research, Management and Policy. John Wiley \& Sons, Hoboken, USA.

Symonds, M.R. \& Moussalli, A. (2011) A brief guide to model selection, multimodel inference and model averaging in behavioural ecology using Akaike's information criterion. Behavioral Ecology and Sociobiology, 65, 13-21.

Turner, M.D., Butt, B., Singh, A., Brottem, L., Ayantunde, A. \& Gerard, B. (2016) Variation in vegetation cover and livestock mobility needs in Sahelian West Africa. Journal of Land Use Science, 11, 76-95.

Tyrrell, P., Russell, S. \& Western, D. (2017) Seasonal movements of wildlife and livestock in a heterogenous pastoral landscape: implications for coexistence and community based conservation. Global Ecology and Conservation, 12, 59-72.

Woodroffe, R., Frank, L.G., Lindsey, P.A., ole Ranah, S.M. \& Romanach, S. (2007) Livestock husbandry as a tool for carnivore conservation in Africa's community rangelands: a case-control study. Biodiversity and Conservation, 16, 1245-1260.

ZuUR, A.F., Ieno, E.N. \& ElPhick, C.S. (2010) A protocol for data exploration to avoid common statistical problems. Methods in Ecology and Evolution, 1, 3-14. 